\section{The role of network administrative organizations in the development of social capital in inter-organizational food networks}

\author{
Lefebvre, Virginie M. - Molnár Adrienn - \\ Gellynck, Xavier \\ Ghent University, Faculty of Bioscience Engineering, \\ Department Agricultural Economics, Gent \\ Virginie.Lefebvre@Ugent.be
}

\section{SUMMARY}

This paper is concerned with the role of network administrative organizations (NAOs) in the development of social capital in interorganizational networks aiming at supporting their members to innovate in the food sector through interacting with one another. A multi-case study approach is used whereby three Belgian interorganizational networks are investigated i.e. Wagralim, Réseau-Club and Flanders Food.

Our study shows that there are many options available to NAOs to build social capital within the networks they are responsible for We propose to categorize these options in three main distinct groups. First, NAOs may nurture the development of social capital within the network through creating 'space'boundary objects which appear, in our study, to be an absolute precondition for the development of interactions and hence creation of ties between network members. Second, NAOs may impact the development of social capital by favoring certain members - or set of members - over others due to their characteristics such as good reputation, possession of common past experiences, multidisciplinary experiences, non-conflicting goals, similarity in terms of sector of activity and/or experience level and common mindset towards information exchange. Third and finally, NAOs may foster social capital development by enhancing effective communication between members on the one hand, and between members and the NAOs'coordination and decision bodies on the other hand, via a clear mandate, network decision making bodies composed of members, the use of ex-post evaluations and formal governance mechanisms (e.g. legal contracts), and the selection of staff endowed with a proactive and perspective taking behavior and able to show neutrality when conflict arise.

Keywords: inter-organizational networks, social capital, network management, network administrative organization

\section{INTRODUCTION}

Enterprises are often embedded in a wide variety of networks of social, professional, and exchange relationships with other organizational actors such as their suppliers, customers, competitors, or other entities within or outside their domain of activity or country (Gulati, Nohria et al. 2000). These interorganizational networks are today widely recognized as being the locus of innovation and hence sustainable growth as they allow enterprises to access to new technologies, knowhow and resources, shorten innovation time, increase the flexibility of their operation, reduce transaction costs, enjoy economies of scale, and share risk and uncertainty among network members (Powell et al., 1996; Kale et al., 2000; Souitaris, 2001; Hallikas et al., 2004; Lee et al., 2010). In such a perspective, having access to high quality networks is of utmost importance for enterprises, especially for those lacking the necessary resources and capabilities to successfully innovate by sole means of in-house activities; such as often do small and medium enterprises (SMEs) (Nooteboom, 1994; Narula, 2004; Hausman, 2005). However, it appears that not every enterprise is able to adequately build networks for innovation. In such a context, a new type of organizations has emerged aiming at acting as intermediaries between the enterprises in demand of innovation related inputs and the organizations able to provide such inputs (e.g. universities, research centers, other enterprises, specialinterest groups, industry organizations) (Howells, 2006; Klerkx and Leeuwis, 2009).

These "intermediary" organizations - also known as third parties, brokers and bridging organizations have received a wide attention in literature, especially regarding their different innovation brokerage functions (Howells, 2006; Winch and Courtney, 2007) and their embeddedness within the innovation system (Huggins, 2000; Sapsed et al., 2007). Still, whether and how these organizations contribute to the innovation process remains poorly investigated (Sapsed et al., 2007; Johnson 2008). With this paper, we will attempt to fill in this gap by exploring different types of intermediary organizations with a focus on how their strategy and organization influence the innovation process in SMEs. More specifically, we aim at answering the following research question: "How can intermediary organizations influence the development of social capital in interorganizational networks in the food sector?" The choice to focus on one particular sector i.e. the food sector resides in the fact that such sectoral approach is often preferred when investigating innovation as innovation is known to be highly dependent on the sectoral specificity of learning, knowledge and actors (Malerba, 2006).

The paper is structured as follow. Section 2 reviews the relevant literature on IPP and intermediary organizations based on which a research framework is developed. Next, section 3 presents the methodology of the empirical research. Section 4 focuses on the findings of the empirical research. Finally, section 5 highlights the main issues related to our findings and provides direction for future research

\section{LITERATURE REVIEW}

\section{Innovation process and its determinants}

Innovation is often approached in two different ways. Some authors have conceived innovation as an outcome and tried to determine the contextual conditions under which an enterprise can innovate while others have conceived it as a process and sought to understand 
how it develops to become part of the daily activities of an enterprise (Damanpour and Gopalakrishnan, 1998). In this paper, we approach innovation as an outcome and define it following Pittaway et al. (2004) as the successful exploitation of ideas into new products, new processes, new forms of organization and new markets. Contrary to invention, innovation is not a simple inventive step as it involves the elements of commercialization (Chen and Guan, 2011). It is recognized to be the result of several functionally distinct but interdependent subprocesses which together structure what is commonly known as the innovation production process (Chen and Guan, 2011) or innovation value chain (Roper et al., 2008). Although different terminologies are used for each of these subprocesses, a complete innovation production process (IPP) usually starts with a phase of knowledge accumulation during which the enterprise acquires and accumulates knowledge and innovation experiences. It then continues with a phase of knowledge transformation during which the knowledge accumulated is translated into innovation outputs such as new or improved technology or product prototypes thanks to the allocation of resources - both R\&D and non-R\&D related - to the innovation development. Finally it ends with a phase of knowledge exploitation during which the enterprise derives economic profits from the innovation outcomes (Hansen and Birkinshaw, 2007; Roper et al., 2008; Chen and Guan, 2011).

The literature includes a large number of factors that affect an enterprise's rate of innovation; and hence its IPP. These factors, labeled "determinants of innovation", either derive from a wide range of firm level characteristics or functions (for a review see
Souitaris, 2001), or from the features of networks in which enterprises are embedded. In this paper, we will restrict ourselves to the latest.

Scholars who have started to look at the contribution of networks to the IPP, have especially focused on the knowledge accumulation phase, and in particular on knowledge sharing as this process seems the most difficult in its implementation (Lin et al., 2012). The social capital theory provides an interesting perspective from which to explain knowledge exchange. It highlights three dimensions of interorganizational relationships affecting the degree of deployment of knowledge resources and engagement in knowledge exchange activity within interorganizational networks: the structural dimension, the cognitive dimension and the relational dimension. The first one refers to the pattern of relationships between network actors and can be analyzed from the perspective of network ties and network configurations (i.e. hierarchy, density, connectivity). The cognitive dimension involves the resources providing shared meaning and understanding between network members and can be related to shared goals and shared language and codes. Finally, the relational dimension represents the kind of personal relationships people develops with each other through a history of interactions. It focuses on trust, norms and identification (Nahapiet and Ghoshal, 1998; Inkpen and Tsang, 2005; Pérez-Luño et al., 2011). A working definition for each facet of the social capital dimensions can be found in table 1.

In the next sections, we continue reviewing the literature addressing the context of innovation in the food sector and the importance of intermediary organizations in supporting the innovation process in the sector.

Table 1.

Social capital

\begin{tabular}{|c|c|c|c|}
\hline \multirow{2}{*}{ Dimension } & Social capital & \multirow{2}{*}{ Definition } & \multirow{2}{*}{ References } \\
\hline & Facet & & \\
\hline Structural & Network ties & Specific ways through which the actors are related & Inkpen and Tsang (2005) \\
\hline \multirow[t]{2}{*}{ Cognitive } & Shared language and codes & $\begin{array}{l}\text { "Means by which people discuss and exchange information, ask } \\
\text { questions, and conduct business in society" }\end{array}$ & Inkpen and Tsang (2005) \\
\hline & Shared goals & $\begin{array}{l}\text { "Degree to which network members share a common } \\
\text { understanding and approach to the achievement of network tasks } \\
\text { and outcomes" }\end{array}$ & Inkpen and Tsang (2005) \\
\hline \multirow[t]{3}{*}{ Relational } & Trust & $\begin{array}{l}\text { "Willingness of a party (the trustor) to be vulnerable to the actions } \\
\text { of another party (the trustee) based on the expectation that the } \\
\text { other will perform a particular action important to the trustor, } \\
\text { irrespective of the ability to monitor or control that other party" }\end{array}$ & Mayer et al. (1995) \\
\hline & Identification & $\begin{array}{l}\text { Process whereby individuals see themselves as one with another } \\
\text { person or group of people }\end{array}$ & Nahapiet and Ghoshal (1998) \\
\hline & Norms & Degree of consensus in the social system & Nahapiet and Ghoshal (1998) \\
\hline
\end{tabular}

\section{Innovation in food SMEs}

The food sector is known as a low-tech industry characterized by a low rate of innovations (Kirner et al., 2009). Only $2 \%$ of really new products are regarded as radical or new to the category (Kühne, 2011). Still, innovation - i.e. new products, processes, services, market or organizations - is an important instrument for food enterprises to stand out from competitors and thus remain sustainable (Menrad, 2004). As such, some scholars have started to study the enablers and disablers of the innovation process in the sector. One prominent study is the survey conducted by Lienemann and Lehnert (2005) which indicates several barriers in connection with research cooperation in the German food sector. The most important barriers identified refer to the length and complexity of the project procedure, the different goal statements and to the availability of public funds and risks concerning information and knowledge flows.

Besides the literature focusing directly on the determinants of the innovation process in the food sector, the literature on innovation in SMEs certainly 
offers valuable inputs to understand the innovation process in the food sector; the food sector being composed of more than $99 \%$ of SMEs (Kühne, 2011). SMEs are more than simply smaller versions of large-scale enterprises, especially when it relates to innovation. Following Batterinck et al. (2010), they possess characteristic features which can be considered either as strengths or weaknesses for the innovation process. Possible strengths of SMEs are motivated management and labor, effective internal communication, little bureaucracy, and closeness between customers and managers. Probable weaknesses of SMEs compared to larger-scale enterprises are scarcity of resources, limited absorptive capacity, overinvolvement by the owner in operational level decisions, and lack of long term strategic thinking, detailed market information and functional expertise (Hausman, 2005; Batterinck et al., 2010; Bruns, 2010). In literature, such weaknesses often oblige SMEs to establish relationships with external actors to obtain the appropriate information in order to innovate (Camison, 2008; Batterinck et al., 2010). Still, research shows that there are many factors impeding the establishment of such relationships. Some of these factors relate to the divergence in work culture between enterprises and research institutions, the high investment in coordination efforts and to the power imbalance between partners (Batterinck et al., 2010; Bruns, 2010).

In the context of the potential challenges the above identified barriers might involve, a new type of organizations has emerged called commonly "intermediary organizations" (Howells, 2006; Klerkx and Leeuwis, 2009). The literature regarding this type of organization is shortly reviewed in the next section.

\section{Intermediary organizations}

Following Howells (2006), an intermediary organization is defined as "an organization or body that acts as an agent or broker in any aspect of the innovation process between two or more parties. Such intermediary activities include: helping to provide information about potential collaborators; brokering a transaction between two or more parties; acting as a mediator, or go-between, bodies or organizations that are already collaborating; and helping find advice, funding and support for the innovation outcomes of such collaborations". Such a definition encompasses a wide variety of organizations, ranging from innovation consultants providing intellectual properties advices and commercial information to agencies aiming at fostering competence building, networking or offering incubating activities (Edquist, 2006). In this paper, we will focus specifically on intermediary organizations which are closely related to the innovation brokers of Winch and Courtney (2007) and the network administrative organizations (NAOs) of Provan and Kenis (Provan and Kenis, 2007). The type of intermediary organizations we are interested in differentiates from others by being specifically set up to manage an existing network of organizations and its activities in order to enable organizations to learn and innovate. These organizations may only consist of a single individual or they may be a formal organization, consisting of an executive director and staff addressing the operational decisions and a board addressing strategic-level network concerns. Moreover, they may either be established by the members themselves or through mandate; and in that case, are often set up when the network first forms, to stimulate its growth through targeted funding and/or network facilitation and to ensure that network goals are met (Provan and Kenis, 2007). The decision to focus on this particular type of intermediary organizations is justified by the fact that many European countries have started to support their establishment with the aim of encouraging innovation in SMEs, and hence economic growth and employment (Hoffman et al., 1998; Kolodny et al., 2001; Capron, Cincera et al. February 2000). For the sake of clarity, we will use the term of network administrative organizations when we refer to this type of intermediary organizations in the rest of this article.

In the literature, intermediary organizations are known to perform three basic functions: (a) demand articulation, (b) network formation and (c) innovation process management (Klerkx and Leeuwis, 2009). Demand articulation - also named innovation initiation (Batterinck et al., 2010) - involves the diagnosis and analysis of problems and articulation of needs of enterprises in demand for innovation inputs (Howells, 2006; Klerkx and Leeuwis, 2009). Network formation - also known as network brokerage (Klerckx and Leeuwis, 2008), network design (Dhanaraj and Parkhe, 2006) or network construction (Lee et al., 2010) - relates to facilitating the establishment of connections between the demand and supply side for innovation (i.e. scanning, scoping, filtering and matchmaking of possible cooperation partners). Finally, innovation process management - also labeled as network management (Lee et al., 2010) or network orchestration (Dhanaraj and Parkhe, 2006) refers to enhancing collaboration through developing alignment, communication and learning among partners (Klerckx and Leeuwis, 2008; Lee et al., 2010).

The focus of this study is to contribute to the understanding of the role of intermediary organizations in the development of social capital in inter-organizational networks in the food sector in particular. We believe that intermediary organizations, through the three functions they are known to perform (i.e. demand articulation, network composition and innovation management process), impact the three dimensions of social capital affecting knowledge exchange. In this study, we therefore are concerned with the development of network ties, shared language and goals, trust, identification and norms.

\section{METHODOLOGY}

In order to answer the research question, a case study approach was used as it allows, following Yin (2009) and Eisenhardt (1989), to study a contemporary phenomenon which is difficult to separate from its context, and its dynamics.

Three formal interorganizational networks and their respective NAO were selected for analysis in Belgium. Selection criteria used to sample the case studies related to age, scope (i.e. food, innovation or SMEs focused), orientation (i.e. regional, national or international) and funding (i.e. public, private, public-private). For each case study, at least ten semi-structured interviews were conducted with network actors and management staffs of NAOs in order to cover the different triple helix 
actors between January and June 2011. In addition to the interviews, complementary documents were collected in order to increase construct validity. All interviews were tape recorded and entirely transcribed. The transcripts were sent by e-mail to the interviewees for review which contributed to their validation. For each network, a detailed case description was developed. A cross-case synthesis was then performed in order to compare the different networks and identify possible differences and similarities (Yin, 2009).

\section{CASE DISCUSSION AND FINDINGS}

The following sections present results from the crosscase analysis to explain different NAOs' approaches to social capital development in interorganizational networks. The objective is not to compare different NAOs' approaches in order to identify the most appropriate one for social development in interorganizational networks; rather we aim at illustrating the range of options available to NAOs to develop social capital in specific interorganizational networks. We first start with a general description of each case to continue with the comparison of the cases with respect to NAO's practices employed for social capital development.

\section{Cases general description}

Wagralim is a public-private funded regional network which was developed in 2006 through the initiative of the Walloon regional government. The network was created with the aim to foster the competitiveness of enterprises in the food industry and increase business and employment in the sector by bringing enterprises together, developing the spirit of innovation, improving the profitability of food chains and encouraging the positioning of enterprises in growing market. The NAO of Wagralim consists of a Board of Directors made of 10 representatives from the food industry, 5 scientific representatives and 1 representative from trade associations; an operation unit consisting of an executive director and 4 staff members; and several "task forces" uniting representatives from the food manufacturing world and the world of science and education to discuss the development of the 4 selected priority areas (i.e. health foods, innovative production and conservation technology, bio-packaging and the development of durable food industry networks). The operational unit is responsible for organizing and managing different activities among which R\&D projects, training programs and advisory/support activities. The network counts at the moment 187 members, half of which being research centers and laboratories/divisions of universities and half of which being food producing SMEs.

Réseau-Club is a private funded regional network which was developed in 1999 through the initiatives of three SMEs having participated to a training program organized by ICHEC-PME training centre belonging to ICHEC Brussels Management School. During this training program oriented towards SMEs and their dayto-day managerial problems, a strong group dynamic was developed among the participants perceived as very beneficial but which was fading away soon after the program ended. The primary objective of setting up the network was therefore to not lose this dynamic. The idea was that as soon as the program, organized every year, was finished, all participants were automatically becoming members of the network. Today, the network has for main objective to be a group of SME's managers of various sectors having participated in the SME-oriented training program and to develop network activities in line with the needs of SMEs. The NAO of Réseau-Club consists of one individual of the ICHEC-PME training centre staff i.e. the "network coordinator"; and of a Network Committee made up of about ten network members. The network coordinator is responsible for managing different activities which range from symposia, conferences and round-table events to company visits, short-length training programs, newsletters and virtual web space. The network counts currently 735 members who are all SMEs and which together cover nine different sectors among which the food sector.

Flanders' FOOD was launched by the Flemish government in cooperation with the food industry in 2005 and is subsidized by the former. It aims at strengthening the competitive power of Flemish food firms by stimulating innovation. The focus lies on the collaboration of food firms, especially SMEs, and research institutions by means of collaborative projects. The NAO of FlandersFood consists of a Board of Directors made of 17 representatives of small and large Flemish food companies and of an Operational Unit consisting of a vice president, 5 scientific employees - all bioscience engineering - and 2 administrative employees. In addition there is a Core Steering Committee - consisting of R\&D managers from food companies - who fulfil a more practical role as representatives of the Flanders' FOOD members. The network counts today 232 company members among which more than half are food processing SMEs.

\section{Structural dimension}

As mentioned previously, NAOs are set up specifically to manage a network. In such a perspective, "managing" the network - in terms of the structural dimension of social capital - may relate to the development of ties within the existing network or to the attempt to develop it further through attracting new members.

\section{Creating ties within the existing network}

In order to have the opportunity for interorganizational knowledge sharing, firms must necessarily establish communication with other organizations (Chen and Guan, 2011; Pérez-Luño et al., 2011). In literature, it is known that communication across firm boundaries can be facilitated through boundary objects. Boundary objects are physical or virtual artefacts that allow groups to coalesce and form stable, if transitory, working relationships. They can be technologies, drawings, set of rules, research projects or documents and they may be mobilized by an intermediary organization in charge of making effective connections between two or more organizations (Kimble et al., 2010). In all three investigated cases, strong efforts are deployed by the NAOs to develop such boundaries objects. In this section, we discuss those creating a 'space' for interaction per se. We will 
discuss the ones framing the interaction, and therefore more related to the other dimensions of social capital, in later sections.

From the cases, 'space' boundary objects may differ on several dimensions. A first dimension relates to whether the boundary object offers the opportunity to network members to meet in person or virtually. Examples of "concrete" boundary objects from the cases are R\&D projects, seminars, conferences, 'aperitifs', training programs and firm visits. An example of a "virtual" boundary object is the web-platform of experiences offered by Réseau-Club through which members can exchange their experiences. A second dimension involves the size of the group of members whom will be linked to one another through the boundary object. From the cases, the size of this group is highly variable; it ranges from 3 members for certain R\&D projects of Wagralim to 600 members on average for the symposia Réseau-Club organizes every two years. A third dimension refers to the extent to which the boundary object 'directs', 'frames' and 'controls' the interactions between network members. From all the boundary objects identified in the cases, the 'aperitifs' are certainly the ones leaving the most freedom in interactions. On the opposite, the R\&D projects of Wagralim, because they are characterized by clear objectives, timing and tasks allocation, are the boundary objects where the interactions are the most constrained.

Besides ensuring the creation of boundary objects, NAOs must also logically assure that these boundary objects suit members' preferences and needs in order to enhance boundary objects' attractiveness towards members and hence create ties within the network. From the cases, this implies first that NAOs must identify these preferences and needs and second that they are able to articulate them properly. In the cases, two ways are used to identify member's preferences and needs, both exploited by all NAOs investigated. First, preferences and needs can be identified via the formal organs of the NAOs - such as the Board of Directors and the Task Forces of Wagralim or the Network Committee of Réseau-Club - when these comprise network members. Second, they can be identified through conducting ex-post evaluations. Regarding the articulation of preferences and needs, it appears from the cases that it can be influenced by the flexibility of boundary objects - constituting a fourth dimension for boundary objects - which refers to the extent to which they are malleable by members. Example of rather flexible boundary objects are the R\&D projects of Wagralim which can be shaped for their objectives and strategy by the members themselves, and especially the SMEs, as they need to be initiated by the latest. In addition, the open-mindedness of the staff taking decisions concerning the network and its activities and therefore boundary objects may also play a role in the articulation of members' preferences and needs. Open-mindedness here refers to the ability of NAOs' staff in charge of the decision making process to leave their comfort zone and engage in more unknown innovation paths. It seems to be influenced by breadth of experiences. As a member of Wagralim mentioned:
'Network XXX for example is lead by a former product manager-CEO-business developer. When you meet him, you understand immediately he opens everything. The executive director of Wagralim, whom I like very much, is a former $R \& D$ manager, so it's logical in Wagralim to go into research. It's natural because if there is a research project he will feel more comfortable ... In Wagralim, it never has been an obligation to focus on the innovation at the level of the product ... in other networks, they went way further in the definition of innovation.'

It should be mentioned that from the cases, members' preferences and needs seem to vary widely. As such, one can assume that an NAO able to develop many and diverse boundary objects within a network increases the chance that members' preferences and needs are fulfilled.

Besides ensuring the creation of boundary objects aligned with members' preferences and needs, it becomes visible from the cases that NAOs must also assure that these boundary objects are promoted properly within the network. From the cases, effective promotion mainly relies on the proactiveness and communication skills of NAOs' operational unit's staff or network coordinator. Communication skills refers here to the ability of staff to communicate with members through using "member language" - and more specifically "SME language" - and to do so via identifying the most suitable communication channels for SMEs. In our study, the most suitable communication channels appear to be the ones where NAO's staff is directly involved with members, and preferably through personalized contacts.

'We need to know that in the world of SMEs ... the word innovation means at the level of academia ... therefore many SMEs say, when speaking about innovation, that it's not their business ... But when you vulgarize innovation and put it in business language, then we see that enterprises understand the advantages of innovation ... Wagralim still needs to work on that. When you look at Flanders Food, they are very active at trying to speak in an easy language ... at saying things in easy way.

'I am a member of Wagralim since 2 years ... I received e-mails very regularly but it is impersonal ... They are about some calls for this or that ... we have the impression that there are people in their office who bombard us with e-mails while waiting that something come back to them. They are not proactive at all or at least at my level ... We don't known each other, they never called us ... we are just in their data base at least that's how I feel.'

As such, effective promotion is very much linked to the ability of the NAOs' staff for perspective taking also known as role-taking or cognitive empathy which refers to the ability to imaginatively reconstruct the worlds of others in order to understand their cognitive framework, attitudes and emotions (Bond III. et al., 2004).

\section{Expanding the existing network}

From the cases, three factors seem to influence the capacity of NAOs to expand the existing network. A 
first factor refers to whether the NAO is able to make itself, and the network is responsible for, visible to its target audience i.e. SMEs. Our study suggests that visibility can be ensure through establishing connections with other support organizations already connected with SMEs, but also through a clear mandate; thus extending the findings of Kolodny et al. (2001) who had linked visibility essentially to the first mentioned aspect. Enhancing visibility through specifying objectives and target audience seems from our study to be especially required in environments where SMEs are confronted to a multitude of innovation support organizations. As one firm respondent pointed out, a clear mandate allows the NAO and its network to stand out of the crowd; suggesting that an NAO actually need to compete against other innovation support organizations to expand its network but also probably retain its members.

'One big challenge in Wallonia is to organize all this mess of associations and organizations of innovation support... I have sometimes difficulties to understand who does what. It is not a problem of communication because now they all have started to write us. They send us beautiful leaflets ... with the list of all their activities ... ZZZ have a very clear mandate like VVV, but they are plenty who don 't.'

A second factor influencing the capacity of NAOs to expand the existing network, involves NAOs' staff proactiveness and communicative skills. Like for promoting boundary objects within the network, proactive staffs with appropriate communicative skills assure that the network is promoted properly in its environment and especially among its target audience.

A third and final aspect relates to demand articulation. Like for the creation of ties within the existing network, the capacity of NAOs to identify and articulate needs of SMEs is also crucial for network expansion. In line with the findings of Batterinck et al. (2010), the cases suggest that the extent to which NAOs are connected with networks of SMEs impact their capacity to identify the preferences and needs of potential new members. Moreover, and as already put forward by Kolodny et al. (2001), articulation of needs is highly dependent upon the ability of the NAOs to connect SMEs with the appropriate sources of information. This suggests the importance for NAOs to attract organizations likely to bring an added value to the network and its members such as organizations benefiting from a high reputation.

'For us, what has been very useful is to establish contact with the lab of Mrs. XXX who is highly reputable internationally ... It's good for us to have good contact with this lab and be able to exchange information with them ...'

\section{Cognitive dimension}

\section{Shared language and codes}

From the cases, shared language and codes seems especially crucial in the scope of multidisciplinary interorganizational networks developed around boundary objects such as the R\&D projects of Wagralim and Flanders Food. It assures that organizations are on the same line in terms of norms and values, therefore smoothing communication and the knowledge exchange process (Brown and Duguid, 2001). From our study, it appears that NAOs may ease the development of shared culture within such interorganizational networks - or at least impact the ability of organizations to adapt to language and codes differences - through two ways. First, they can do so via selecting appropriate partners for the network. Development of shared language in the network is facilitated when the selected network members have already been exposed to the cognitive frames of one another through e.g. sharing some common past experiences or possessing multidisciplinary experiences. Second, and especially in case of members who haven't been exposed to other cognitive frames than theirs, NAOs can ease the development of shared language by assuring that somebody - often the project coordinator who may be a NAOs' staff - plays the role of translator or boundary spanner between project members.

'It was difficult at the beginning to work between businesses and universities ... we didn't have the same objectives, didn't use the same languages ... I think the research coordinator played a big role ... Without a good coordinator, there is no good project. "

As a translator, the project coordinator then accompanies members in the 'socialization process' (Louis, 1980) by which they come to appreciate the values of others. $\mathrm{He} / \mathrm{she}$ actually acts as an 'eye-opener' and as such helps members to think outside of the 'dominant logic' (Bettis and Prahalad, 1995; Lane et al., 2001) they are used to think through. In line with literature (e.g. Brown and Duguid, 2001), our data show that the role of translator is highly dependent upon the extent to which the person performing it possesses multidisciplinary experiences.

\section{Shared goals}

As already suggested by Inkpen and Tsang (2005) and Peters et al. (2010), our study shows that the development of shared goals - whether they are at the level of a member consortium developed around a boundary object or at the level of the whole network - depends on whether the members involved have the opportunity to negotiate these goals and build consensus about them. NAOs can provide members with such opportunity through encouraging and giving them the possibility to participate in the formal organizations of the NAOs in charge of decision making. In addition, our cases suggest that NAOs may foster the development of shared goals by paying a particular attention to the member selection process so that no or few conflicting goals coexist within the same network; these seeming to hamper knowledge sharing within the network.

'The approaches or motivations to become part of the network may sometimes be different. I think there are some people who join to make business right away, and I understand it. But that can be a limitation in the exchanges because if they meet somebody like me, it's not going to work.

Finally, NAOs can also influence the development of shared goals by assuring that somebody - often the project coordinator - or a 'coordination' boundary object - e.g. a consortium agreement - helps aligning members' goals by clarifying common goals and individual tasks.

'The number one success factor is a good coordination. A good coordinator assures ... a good organization and planning. He/she needs to constantly remind the objectives 
of the project to the partners involved. In some projects, some partners were not interested in the project anymore, and therefore did not involve themselves anymore. It was a problem of coordination.'

\section{Relational dimension}

\section{Trust}

Trust is one of the characteristics of a relationship known to impact knowledge transfer which has received the most attention in literature. Some researchers have examined trust in its general terms, while others have sought to identify the predictors of trust and the conditions leading with greater or lesser trust (Levin et al., 2002, 2006). Following Schoorman et al. (1995), trust can be related to the belief in the competence and capability of the other party (competence trust), to the belief in the good intent and concern of the other party (benevolence trust) and to the belief in the attachment to a particular set of principles of the other party (integrity trust). From our study, we learn that benevolence trust and integrity trust are the ones that seem to matter the most in interorganizational networks.

When engaging in interorganizational relationships, it is known that a firm is confronted to a series of tensions or conflicts due to the presence of risk of opportunism, goal divergence and cross-cultural differences (Dyer and Singh, 1998; Kim and R., 1998; Kale et al., 2000; Batt and Purchase, 2004). In the cases we investigated, tensions or conflicts appeared to be especially present in collaborative projects of Wagralim and Flanders FOOD where members expressed their doubts about the reliability of other members, either because these were their direct competitors - and they therefore sensed a greater risk of opportunism - or because they had different ways of doing things (e.g. different perceptions scientists and business have about deadlines) - and in that case they felt tensions due to goal divergence and cross-cultural differences. These tensions and conflicts are known to hamper the development of benevolence trust (risk opportunism and goal divergence) and integrity trust (cross-cultural differences) within the network. An effective management of conflicts and leveling of tensions is therefore required for the development of trust; a task which, in our study, mainly lies with NAOs. To perform this task, NAOs may use legal contracts e.g. the consortium agreements developed by Wagralim and Flanders' FOOD for their R\&D collaborative projects. Legal contracts are known to reduce risk of opportunism and align members' goals (Dyer and Singh, 1998); they are actually examples of 'coordination' boundary objects as they frame interactions by clarifying the expected roles and behaviors of each member. NAOs may also strive to align members' goals through effective communication (see "Shared goals") and reduce cognitive distances between members by playing a role of translator (see "Shared language and codes"). Finally, and in line with the findings of previous research (e.g. Kale et al., 2000; Batterinck et al., 2010), for an effective management of conflicts and leveling of tensions, NAOs must show neutrality towards members and issues at stake and act in the most equitable way possible. From our study, an 'outsider position' seems to impact the ability of NAOs to show such a neutral behavior.
'Sometimes it happens that certain members of a project consortium come to find us [operational unit] to solve a certain problem. It's the advantage we have for not being directly linked to the project, we can have a certain neutrality and play a moderating role.'

\section{Identification}

As already mentioned in the research framework, identification is defined as the process whereby individuals see themselves as one with another person or group of people. From our cases, identification either refers to whether a member identified him/herself with the other members of the network or with the network itself; a distinction which is closely related to the concepts of "interpersonal identities" and "collective social identities" which are both social extensions of the self but differ in whether the social self derive from personalized bonds with specific others or impersonalized bonds derived from common identification with some symbolic or social groups (Brewer and Gardner, 1996). In literature, an individual identifies himself with another or a group when similarities exist between them (Brewer and Gardner, 1996). Similarities may relate to many aspects such as values, age, education, race, etc. but in our study, similarities related to sector of activity and experience level seem to be the ones which matter to activate identification and hence promote voluntary interactions between them.

'I participate less and less to Réseau-Club's activities because first I am the only one coming from Liège and second because I don't have much in common with the other members who are active in other sectors.'

'I was the only working in the food sector, it was difficult for me to develop synergies with the other members.'

'When I joined the network, many members were, like me, children of entrepreneurs who were going to take over the family business ... even if we're not working in the same sector or even if we were competitors, we could still discuss about our daily problems.

'I think it's good if the network has connections with other networks, but they should be of SMEs and not of big enterprises because we don't have much in common with them.'

As such, NAOs can strengthen identification within the network by choosing for a certain level of uniformity among the network members in terms of sector of activity in particular.

\section{Norms}

In literature, several norms have been identified as crucial for knowledge exchange. These involves norms of openness and teamwork, willingness to value and respond to diversity, openness to criticism and tolerance of failure (Nahapiet and Ghoshal, 1998). Our study shows that NAOs can influence the development of these norms conducive to knowledge exchange through three ways. First, they can do so by allocating, during the selection process of new members, a special attention to whether the mindset and culture of the latest are in line with these norms. As an example, the network coordinator of Réseau-Club invests a lot of effort in the selection process of new network members. A visit is paid to every potential new member in order to check whether 
they present a certain degree of openness, one of the core values of the network.

'We select the participants for our training program ourselves. Before the program starts, we meet each applicant and check whether they are open, ready to receive and share information ... This selection process is important in order to assure that there is a certain dynamic of exchange.'

Moreover, the network coordinator also prevents cultural mismatch between network members by encouraging them to look themselves for new network members. Second, NAOs can encourage newcomers to adopt norms conducive to knowledge exchange by creating an environment favorable to 'self-reflection' or 'introspection'. A possible approach to create such an environment relate to directing the attention of members to their own collaborative and relationships behavior through the organization of courses about human resources like ICHEC-PME does.

'During the training program, we addressed different themes such as about human resources. This actually obliged me to reflect upon my beliefs.'

Finally, NAOs can foster newcomers to adopt norms conducive to knowledge exchange by showing the 'good-example'. ICHEC-PME for example seeks to create opportunities for newcomers to meet "older members" so they can learn from the latest the networkspecific norms and expected behaviors. or in the wordings of Louis (1980) 'test and validate their perceptions and interpretations of the new-setting' - in the present case the network.

'During one presentation, a much known CEO, member of the network, was invited as a guest-speaker. He showed us his daily company data, not only averages. It really impressed me and now I also share more easily my data with others ... It was the same with the CEO of ... we just trust each other.'

\section{DISCUSSIONS AND IMPLICATIONS FOR THEORY AND PRACTICE}

The aim of this article was to contribute to the understanding of the role of intermediary organizations, and especially of network administrative organizations (NAOs) in the development of social capital in interorganizational networks in the food sector in particular. Our study shows that there are many options available to NAOs to build social capital within the networks they are responsible for; options which we propose to categorize in three main distinct groups. First, NAOs may nurture the development of social capital within the network through creating 'space' boundary objects which appear, in our study, to be an absolute precondition for the development of interactions and hence creation of ties between network members. Second, NAOs may impact the development of social capital by favoring certain members - or set of members - over others due to their characteristics such as good reputation, possession of common past experiences, multidisciplinary experiences, non-conflicting goals, similarity in terms of sector of activity and/or experience level and common mindset towards information exchange. Third and finally, NAOs may foster social capital development by enhancing effective communication between members on the one hand, and between members and the NAOs' coordination and decision bodies on the other hand, via a clear mandate, network decision making bodies composed of members, the use of ex-post evaluations and formal governance mechanisms (e.g. legal contracts), and the selection of staff endowed with a proactive and perspective taking behavior and able to show neutrality when conflict arise.

Although the aim of the paper was not to identify the most appropriate NAOs' approaches for social capital development in interorganizational networks, this study reveals that certain approaches may be preferred over others depending on the type of innovation targeted (i.e. new products, new processes, new forms of organization and new markets) and the 'moment' in the knowledge accumulation phase (i.e. generation of ideas or targeted accumulation of information). As an example, 'space' boundary objects leaving the most freedom for interactions are probably the one the most propitious for the generation ideas, especially knowing that the serendipitous nature of innovation makes it impossible to predict the exact nature and timing of innovation (Dhanaraj and Parkhe, 2006). Further research is required to investigate the adequacy of approaches towards social capital and innovation type and moment.

Finally, once should keep in mind that although strong ties - developed through social capital - are known to lead to better knowledge exchange and hence innovation development, they may also have a dark side (e.g. Alajoutsijarvi et al., 2001). Involved actors may lose their autonomy regarding decision making because influenced by others or suffer from reputational damage through actions of other members (Christopher and Gaudenzi, 2009). They may also see their performance decrease if they persist with $R \& D$ projects that underperform (Ritter et al., 2004) and miss opportunities external to the network because 'blinded' by the latest. Whether and how NAOs play a role in managing the dark side of strong ties may be an interesting research question to be explored in the scope of future research.

\section{ACKNOWLEDGMENT}

The research leading to these results has received funding from the European Union Seventh Framework Program (FP7/2007-2013) under grant agreement $\mathrm{n}^{\circ}$ 245301 NetGrow - "Enhancing the innovativeness of food SMEs through the management of strategic network behavior and network learning performance". The information in this document reflects only the authors' views and the Community is not liable for any use that may be made of the information contained therein. 


\section{REFERENCES}

Alajoutsijarvi, K.-Eriksson, P.-Tikkanen, H. (2001): Dominant metaphors in the IMP network discourse: 'the network as a marriage' and 'the network as a business sytem'. International Business Review. 10: 91-107.

Batt, P. J.-Purchase, S. (2004): Managining collaboration within networks and relationships. Industrial Marketing Management. 33: 169-174.

Batterinck, M. H.-Wubben, E. F. M.-Klerkx, L.-Omta, S. W. F. (2010): Orchestrating innovation networks: The case of innovation brokers in the agri-food sector. Entrepreneurship and Regional Development. 22. 1: 47-76.

Bettis, R.-Prahalad, C. (1995): The dominant logic: retrospective and extension. Strategic Management Journal. 16. 1: 5-14.

Bond III., E. U.-Walker, B. A.-Hutt, M. D.-Reingen, P. H. (2004): Reputational Effectiveness in Cross-Functional Working Relationships. Product Development \& Management Association. 21: 44-60.

Brewer, M. B.-Gardner, W. (1996): Who is this "We"? Levels of Collective Identity and Self Representations. Journal of Personality and Social Psychology. 71. 1: 83-93.

Brown, J. S.-Duguid, P (2001): Knowledge and Organization: A Social-Practice Perspective. Organization Science. 12. 2: 198213

Bruns, M. (2010): Inter-organisational innovation processes in the agrifood industry: An approach to improving management support services applied to the meat industry. Institut für Tierwissenschaften. Bonn, Rheinischen Friedrich-Wilhelms-Universität. Doktor der Ernährungs- und Haushaltswissenschaften.

Camison, C. (2008): Learning for environmental adaptation and knowledge-intensive services: the role of public networks for SMEs. The Service Industries Journal. 28 6: 827-844.

Capron, H.-Cincera, M.-Dumont, M. (2000): The National Innovation System of Belgium: the Institutional Profile. CESIT. Universiteit Antwerpen. Discussion Papers. No 2000-01.

Chen, K.-Guan, J. (2011): Mapping the innovation production process from accumulative advantage to economic outcomes: A Path modelling approach. Technovation. 31: 336-346.

Christopher, M.-Gaudenzi, (2009): Exploiting Knowledge across Networks through Reputation Management. Industrial Marketing Management. 33. 2: 191-107.

Damanpour, F.-Gopalakrishnan, S. (1998): Theories of organizational structure and innovation adoption: the role of environmental change. Journal of Engineering and Technology Management. 15: $1-24$.

Dhanaraj, C.-Parkhe, A. (2006): Orchestrating innovation networks. Academy of Management Review. 31. 3: 659-669.

Dyer, J. H.-Singh, H. (1998): The Relational View: Cooperative Strategy and Sources of Interorganizational Competitive Advantage. The Academy of Management Review. 23. 4: $660-679$.

Edquist, C. (2006): Systems of Innovation Perspectives and Challenges. [In: Fagerberg, J.-Mowery, D. C.-Nelson, R. R. (eds.) The Oxford handbook of innovation.] Oxford University Press Inc. NewYork.

Eisenhardt, K. (1989): Building theories from case study research. Academy of Management Review. 14. 4: 532-550.

Gulati, R.-Nohria, N.-Zaheer, A. (2000): Strategic networks. Strategic Management Journal. 21: 203-215.

Hallikasa, J.-Karvonenb, I.-Pulkkinenb, U.-Virolainenc, V. M.Tuominena, M. (2004): Risk management processes in supplier networks. International Journal Production Economics. 90: 4758.
Hansen, M. T.-Birkinshaw, J. (2007): The Innovation Value Chain. Harvard Business Review. 85. 6: 121-130.

Hausman, A. (2005): Innovativeness among small businesses: Theory and propositions for future research. Industrial Marketing Management. 34: 773-782.

Hoffman, K.-Parejo, M.-Bessant, J.-Perren, L. (1998). Small firms, $\mathrm{R} \& \mathrm{D}$, technology and innovation in the UK: a literature review. Technovation. 18. 1: 39-55.

Howells, J. (2006): Intermediation and the role of intermediaries in innovation. Research Policy. 35: 715-728.

Huggins, R. (2000): The success and failure of policy-implanted inter-firm network initiatives: motivations, processes and structure. Entrepreneurship and Regional Development. 12: 111-135.

Inkpen, A. C.-Tsang, E. W. K. (2005): Social capital, networks, and knowledge transfer. Academy of Management Review. 30. 1: 146-165.

Johnson, W. H. A. (2008): Roles, resources and benefits of intermediate organizations supporting triple helix collaborative R\&D: The case of Precarn. Technovation. 28: 495-505.

Kale, P.-Singh, H.-- Perlmutter, H. (2000): Learning and Protection of Proprietary Assets in Strategic Alliances: Building Relational Capital. Strategic Management Journal. 21. 3: 217-237.

Kim, W. C.-Mauborgne, R. (1998): Procedural justice, strategic decision making and the knowledge economy. Strategic Management Journal. 19. 4: 323-338.

Kimble, C.-Grenier, C.-Goglio-Primard, K. (2010): Innovation and knowledge sharing across professional boundaries: Political interplay between boundary objects and brokers. International Journal of Information Management. 30: 437-444.

Kirner, E.-Kinkel, S.-Jaeger, A. (2009): Innovation paths and the innovation performance of low-technology firms - An emprical analysis of German industry. Research Policy. 38. 3: 447-458.

Klerckx, L.-Leeuwis, C. (2008): Matching demand and supply in the agricultural knowledge infrastructure: Experiences with innovation intermediaries. Food Policy. 33: 260-276.

Klerkx, L.-Leeuwis, C. (2009): Establishment and embedding of innovation brokers at different inovation system levels: Insight from the Dutch agricultural sector. Technological Forecasting \& Social Change. 76: 849-860.

Kolodny, H.-Stymne, B.-Shani, R.-Figuera, J. R.-Lillrank, P. (2001): Design and policy choices for technology extension organizations. Research Policy. 30: 201-225.

Kühne, B. (2011): Understanding Innovation Capacity in Food Chains: The European Traditional Food Sector, Ghent University.

Lane, P. J.-Salk, J. E.-Lyles, M. A. (2001): Absorptive capacity, learning, and performance in international joint ventures. Strategic Management Journal. 22: 1139-1161.

Lee, S.-Park, G.-Yoon, B.-Park, J. (2010): Open innovation in SMEs - An intermediated network model. Research Policy. 39: 290-300.

Levin, D. Z.-R. Cross, R.-Abrams, L. C. (2002): Why should I trust you? Predictors of Interpersonal Trust in a Knowledge Transfer Context. Academy of Management meetings. Denver.

Levin, D. Z.-Whitener, E. M.-Cross, R. (2006): Perceived trustworthiness of Knowledge Sources: The moderating Impact of Relationship Length. Journal of Applied Psychology. 91. 5: 1163-1171.

Lienemann, K.-Lehnert, S. (2005): Agrar- und Ernährungsforschung in Deutschland Kooperationschancen erkennen - Innovationen nutzen Ein Handbuch für Politik und Praxis. Bergen/Dumme.

Lin, T. C.-Wu, S.-Lu, C. T. (2012): Exploring the affect factors of knowledge sharing behaviour: The relations model theory perspective. Expert Systems with Applications. 39: 751-764. 
Louis, M. R. (1980): Surprise and Sense making: What newcomers Experience in Entering unfamiliar Organizational Settings. Administrative Science Quarterly. 25. 2: 226-251.

Malerba, F. (2006): Sectoral Systems: How and why innovation differs accross sectors. [In: Fagerberg, J.-Mowery, D. C.-Nelson, R. R. (eds.) The Oxford handbook of innovation.] New-York, Oxford University Press Inc. 380-406.

Schoorman, F. D.-Mayer, R. C.-Davis, J. H. (1995): An integration model of organizational trust. academy of Management Review. 20: 709-734.

Menrad, K. (2004): Innovations in the food industry in Germany. Research Policy. 33: 845-878.

Nahapiet, J.-Ghoshal, S. (1998): Social Capital, Intellectual Capital, and the Orgnizational Advantage. The Academy of Management Review. 23. 2: 242-266.

Narula, R. (2004): R\&D collaboration by SMEs: new opportunities and limitations in the face of globalisation. Technovation. 24. 2 153-161.

Nooteboom, B. (1994): Innovation and diffusion in small firms Theory and Evidence. Small Business Economics. 6. 5: 327347

Pérez-Luño, A.-Medina, C. C.-Lavado, A. C.-Rodríguez, G. C. (2011): How social capital and knowledge affect innovation. Journal of Business Research. 64: 1369-1376.

Peters, L. D.--Johnson, W. J.-Pressey, A. D.-Kendrick, T. (2010): Collaboration and collective learning: networks as learning organizations. Journal of Business \& Industrial Marketing. 25. 6: $478-484$.
Pittaway, L.-Robertson, M.-Munir, K.-Denyer, D.-Neely, E. (2004) Networking and innovation: a systematic review of the evidence. International Journal of Management Reviews. 5-6. 3-4: 137-168.

Powell, W. W.-Koput, K. W.-Smith-Doerr, L. (1996): Interorganizationa collaboration and the locus of innovation: Networks of learning in biotechnology. Administrative Science Quarterly. 41: 116-145.

Provan, K. G.Kenis, P. (2007): Modes of Network Governance: Structure, Management, and Effectiveness. Journal of Public Administration Research and Theory. 18: 229-252.

Ritter, T.-Wilkinson, I. F.-Johnstonc, W. J. (2004): Managing in complex business networks. Industrial Marketing Management 33: $175-183$.

Roper, S.-Du, J.- Love, J. H. (2008). Modelling the innovation value chain. Research Policy. 37: 961-977.

Sapsed, J.-Grantham, A.-DeFilippi R. (2007): A bridge over troubled waters: Bridging organizations and entrepreneurial opportunities in emerging sectors. Research Policy. 36: 1314-1334.

Souitaris, V. (2001): External communication determinants of innovation in the context of a newly industrialized country: a comparison of objective and perceptual results from Greece. Technovation. 21: 25-34.

Winch, G. M.-Courtney, R. (2007): The Organization of innovation brokers: an international review. Technology Analysis \& Strategic Management. 19. 6: 747-763.

Yin, R. K. (2009): Case Study Research - Design and Methods Fourth EDition. Newbury Park. CA. Sage Publications. 